\title{
Deep Seated Dermatophytosis
}

National Cancer Institute

\section{Source}

National Cancer Institute. Deep Seated Dermatophytosis. NCI Thesaurus. Code C35073.

A deep folliculitis due to a cutaneous dermatophyte infection, usually on the legs. It is most commonly caused by trichophyton rubrum and is characterized by the formation of spongy granulomas which persist for three to four months and leaves deep scars. 